\title{
PREANALYTICAL INFLUENCES OF TIME LAPSE AND TYPE OF SAMPLE ON INTACT PTH ASSAYS OF PLASMA AND SERUM ON ADVIA CENTAUR XPT IMMUNOASSAY ANALYSER
}

\author{
Madhulika Kothuru1, Suresh Babu Ganji², Ramadevi Mopuri ${ }^{3}$ \\ 1 Postgraduate Student, Department of Biochemistry, Osmania Medical College, Hyderabad, Telangana, India. \\ ${ }^{2}$ Associate Professor, Department of Biochemistry, MNJIO \& RCC and Osmania Medical College, Hyderabad, Telangana, India. \\ 3Professor and HOD, Department of Biochemistry, Osmania Medical College, Hyderabad, Telangana, India.
}

\section{ABSTRACT}

\section{BACKGROUND}

Measurement of PTH is important in metabolic bone disorders. We conducted a prospective study for a month on the preanalytical influences of time lapse and type of sample on intact PTH assays of plasma and serum. We wanted to study the preanalytical influences of time lapse and type of sample on Intact PTH Assays of Plasma and Serum on ADVIA Centaur XPT immunoassay analyser.

\begin{abstract}
METHODS
This prospective study was conducted in the laboratory of Department of Biochemistry, Osmania Medical College, Hyderabad, for a period of one month in December 2018. Venous blood samples of patients attending General Medicine OPD were included in the study. Venous blood samples from the patients attending OPD were collected from 20 patients and each patient provided both serum and plasma in two separate tubes and at centrifugation; ten specimens were labeled as Cold and another ten as Room Temperature. The Cold set (Groups B \& D) are immediately placed on ice and centrifuged at $4{ }^{\circ} \mathrm{C}$ and separated in to four aliquots for measurement at different timings and stored at $4^{\circ} \mathrm{C}$ till assayed. The second set (A \& C) specimens were treated in same manner at room temperature. Total number of samples, 160 aliquots ( $\mathrm{N}=10 \times 4 \times 4=160)$ were assayed [baseline hr, $24 \mathrm{hr}, 48 \mathrm{hr}$, and 72 hr] on ADVIA Centaur XPT @ Siemens immunoassay analyser.
\end{abstract}

\section{RESULTS}

PTH values from plasma samples were higher than from corresponding serum, irrespective of temperature effect $(p<0.001)$. Time had no significant effect on PTH measurements in EDTA sample both at RT and Cold. At room temperature, serum iPTH was declining with the time lapse by $54 \%$.

\section{CONCLUSIONS}

Preanalytical issues can influence the PTH and affect the clinical decisions; hence laboratories need to set preanalytical protocols.

\section{KEY WORDS}

Intact PTH, Immunoassay, Preanalytical

HOW TO CITE THIS ARTICLE: Kothuru M, Ganji SB, Mopuri R. Pre-analytical influences of time lapse and type of sample on intact PTH assays of plasma and serum on ADVIA centaur XPT immunoassay analyser. J. Evolution Med. Dent. Sci. 2019;8(28):2239-2242, DOI: $10.14260 /$ jemds/2019/490

\section{BACKGROUND}

Measurement of Parathyroid hormone is essential for the diagnosis and management of metabolic bone disease, hypercalcemia, hypocalcaemia and renal osteodystrophy. The effect of specimen type, collection, temperature and storage temperature on the in vitro stability of PTH differs by method employed. Quality of a test performed in clinical laboratory does not merely depend on analytical aspects, but it also needs much care regarding sample handling, time lapse between drawing a sample and performance of required test, storage temperature and added preservatives.[1] Parathyroid hormone, PTH is the major circulating factor regulating factor extracellular calcium concentration. Parathyroid hormone increases the rate of bone metabolism.

'Financial or Other Competing Interest': None.

Submission 24-05-2019, Peer Review 30-06-2019,

Acceptance 05-07-2019, Published 15-07-2019.

Corresponding Author:

Dr. Suresh Babu Ganji,

Associate Professor,

Department of Biochemistry,

MNJIO \& RCC and Osmania Medical College,

Hyderabad, Telangana, India.

E-mail: sushwasa@gmail.com

DOI: $10.14260 /$ jemds $/ 2019 / 490$

\section{(c) $(1) \risingdotseq$}

Depending on the age of the patient, the bone involved, the concentration of hormone in circulation over time, the effect on the bone can be either catabolic or anabolic. The intact PTH peptide (iPTH) consists of 84 amino acids that are sequenced and designated according to reactivity. The $\mathrm{N}-$ terminal or amino terminal 1-34 region of the intact PTH molecule is biologically active. This region of the molecule contains the amino acid sequence that enables PTH to bind to the parathyroid hormone receptors in target tissues and regulate extra cellular calcium concentrations. The middle and carboxy terminal 35-84 region of the intact PTH molecule is biologically inert but possesses immunological reactivity.[2,3] The intact PTH molecule undergoes intra- and extra-glandular proteolytic modifications that produce PTH fragments. Circulating PTH is heterogeneous, existing as both the intact PTH and PTH fragments. Intact PTH is cleared by the kidney and liver, and it has a half-life that is less than 4 minutes. Very little, if any, of the amino-terminal PTH fragments are detected in circulation. The middle and carboxy-terminal PTH fragments vary in size, have longer half-lives, and are primarily cleared in the kidney by glomerular filtration. Under normal conditions, there is a greater relative concentration of circulating middle and carboxy-terminal PTH fragments. In renal insufficiency where glomerular filtration is impaired, the concentration of middle 
and carboxy-terminal PTH fragments is increased. The ratio of the circulating concentrations of intact PTH to middle and carboxy-terminal PTH can vary between individuals, particularly in-patient Quantification of circulating intact PTH assists in the differential diagnosis of hypercalcemia and hypocalcaemia. The measurement of intact PTH using twosite immunoassays provides a more accurate assessment of parathyroid tissue secretory status, especially in patients with renal impairment. [3] Several studies reveal that there are many preanalytical issues like the storage of serum samples for 3 days at room temperature decreased measured PTH in serum samples, an effect not seen with EDTA plasma and EDTA plasma paradoxically increased after storage at $4{ }^{\circ} \mathrm{C}$. Despite evidence that PTH is more stable in EDTA-plasma specimens, inconsistent results from EDTA plasma samples and therefore recommends cold $\left(2-8{ }^{\circ} \mathrm{C}\right)$ collection, centrifugation, and storage until analysis. Correct handling of patient samples is critical to ensure the integrity of the iPTH molecule as iPTH has been demonstrated to be labile and is susceptible to fragmentation. The instability depends on both time and temperature. EDTA Plasma stability at room temperature, $4{ }^{\circ} \mathrm{C}$ and $-70{ }^{\circ} \mathrm{C}$ temp is $8 \mathrm{hrs}$., $72 \mathrm{hrs}$. and 8 months respectively and serum stability at same were, $4 \mathrm{hrs}$, $48 \mathrm{hrs}$. and under study. $[4,5,6,7]$

We wanted to study the preanalytical influences of time lapse and type of sample on Intact PTH Assays of Plasma and Serum on ADVIA Centaur XPT immunoassay analyser.

\section{METHODS}

This prospective study was conducted in the laboratory of Department of biochemistry, Osmania medical college Hyderabad, for a period of one month in December 2018. Venous blood samples of patients attending General medicine OPD were included in the study. This study got approval by the Hospital institutional ethics committee. A total of 160 samples $(\mathrm{N}=160)$ (4 Groups $\mathrm{X} 10$ each sample type $\mathrm{X} 4$ aliquots $=160$ ) were made from 20 patients who were enrolled in to this study. The subjects were randomly divided equal in number into four groups $\mathrm{A}, \mathrm{B}, \mathrm{C}$ and $\mathrm{D}$ as shown in table 1. For Group A and B, blood samples were collected in to EDTA (Anticoagulant) vacutainers for plasma type of sampling and were, for to be kept at room temperature and at $4^{\circ} \mathrm{C}$ respectively. For Group C and D, blood samples were collected in serum (clot activator) tubes for serum type of sampling and were, for to be kept at room temperature and at $4^{\circ} \mathrm{C}$ respectively. From each single patient, two blood specimens of $6 \mathrm{ml} \& 5 \mathrm{ml}$ each were drawn into Becton Dickinson (BD) 6-mL K2 EDTA Vacutainer TM plastic tubes [BD Reference \# 367899] and SST II advance tubes containing gel and clot activator [BD\#ref 367954] BD vacutainers, respectively: both tubes were immediately placed on ice and then centrifuged at $4{ }^{\circ} \mathrm{C}$ (EDTA cold, Group B and Serum cold, Group D). Whereas the second set of ten patients specimens were collected in the same manner in EDTA and SST and centrifuged at room temperature (EDTA RT, Group A and Serum RT, Group C).

All tubes were filled adequately. Each of the four tubes was separated into four aliquots, i.e., A1 to D4. Aliquots from the $\mathrm{B}$ and $\mathrm{D}$ group tubes were maintained at $4{ }^{\circ} \mathrm{C}$ until analysis, whereas aliquots from the $\mathrm{A}$ and $\mathrm{C}$ tubes remained at room temperature and plasma and or serum was separated within one hour by centrifuge machine at $1500 \mathrm{x} g$ for 15 minutes and tubes were kept stoppered and upright at all times. The plasma $(A, B)$ and serum $(C, D)$ were then divided into four aliquots labeled as A1, A2, A3 and A4; B1, B2, B3 and B4. All first aliquots, i.e., A1, B1, C1 and D1 were analysed within first three hours and the value obtained was considered as zero reading or base line reading. The second, third and fourth aliquots (A2 to D4) were analysed after 24 hrs., $48 \mathrm{hrs}$. and $72 \mathrm{hrs}$. respectively. All the samples were analysed on ADVIA CENTAUR XPT (C) Siemens immunoassay analyser using chemiluminescence principle.

\section{Assay Principle}

The ADVIA Centaur iPTH assay is a two-site sandwich immunoassay using direct chemiluminometric technology, which uses $200 \mu \mathrm{L}$ of the sample and constant amounts of an antihuman PTH antibody in the Lite Reagent and an antihuman PTH antibody in the Solid Phase Reagent. The first antibody is a polyclonal goat antihuman PTH (N-terminal 134) antibody labeled with acridinium ester. The second antibody is a biotinylated polyclonal goat antihuman PTH (39-84 region) antibody. Streptavidin in the Solid Phase is covalently coupled to paramagnetic latex particles. A direct relationship exists between the amount of PTH present in the patient sample and the amount of relative light units (RLUs) detected by the system. ${ }^{[8]}$

\section{Statistical Analysis}

The results, Mean and SD of iPTH of those 160 samples (A1 to D4) were entered and analysed through MS excel sheet (\%) and SPSS (Ver. 13.0), we performed within-subject repeatedmeasures ANOVA analyses: the (EDTA/Serum) $\times$ (room

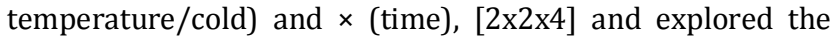
interactions between sample type (plasma or serum) and temperature and sample type and time, were of significance $(\mathrm{P}<0.001)$; we therefore considered the effects of temperature and time separately. Post hoc test applied to know which time period is significantly different from the rest.

\section{RESULTS}

Mean and SD were calculated for the $10 \mathrm{iPTH}$ values for A1 (EDTA RT), and the time lapse with of C1 (Serum RT) at base line, $24 \mathrm{hrs}$., $48 \mathrm{hrs}$. and $72 \mathrm{hrs}$. was compared. In the same manner, A2 Vs C2; A3 Vs C3 and A4 Vs C4 means were compared. Similarly, EDTA cold and Serum cold, i.e., Group B and Group D means were compared (B1 Vs D1, B2 Vs D2, B3 Vs D3 and B4 Vs D4). P-value $\leq 0.001$ was taken as statistically significant. As this study was to determine the mean difference in concentration of PTH from the first reading, so age, gender and PTH levels were not confounding variables. The results of the study showed that the serum samples analysed after $24 \mathrm{hrs}$. from the collection time showed statistically significant difference in their mean concentration value $(p<0.001)$ from the baseline value at room temperature as well as cold storage. The difference is about $11 \%$ decrease in mean PTH concentration. When the samples were analysed at 72 hrs. after collection, they showed decrease of about 54 percent in mean concentration $(p=0.001)$. This is an extremely significant decrease. Post hoc comparisons using the Tukey HSD test indicated that the mean score for the Serum at RT at zero $\mathrm{hr}(\mathrm{M}=27.8, \mathrm{SD}=2.5)$ was significantly different than serum at $\mathrm{RT}$ at $72 \mathrm{~h}(\mathrm{M}=13$, $\mathrm{SD}=2.3)$. 


\begin{tabular}{|c|c|c|c|c|}
\hline Sample Type & \multicolumn{2}{|c|}{ EDTA Plasma } & \multicolumn{2}{|c|}{ Serum } \\
\hline Group Label & $\begin{array}{c}\text { A } \\
\text { EDTA RT } \\
\end{array}$ & $\begin{array}{c}\text { B } \\
\text { EDTA cold } \\
\end{array}$ & $\begin{array}{c}\mathrm{C} \\
\text { Serum RT } \\
\end{array}$ & \begin{tabular}{|c|}
$D$ \\
Serum cold \\
\end{tabular} \\
\hline Storage & $\begin{array}{c}\text { at Room } \\
\text { temperature }\end{array}$ & at $4^{\circ} \mathrm{C}$ & $\begin{array}{c}\text { at Room } \\
\text { temperature }\end{array}$ & at $4^{\circ} \mathrm{C}$ \\
\hline patients & 10 & 10 & 10 & 10 \\
\hline $\begin{array}{c}\text { Aliquots }(4 \times 10=40 \\
\text { each group): } 0,24 \mathrm{~h}, \\
48 \mathrm{~h}, 72 \mathrm{~h}=160\end{array}$ & $\begin{array}{c}\text { A1 (0h), A2 (24h), } \\
\text { A3 (48 h), A4 (72 } \\
\text { h) }\end{array}$ & $\begin{array}{l}\text { B1,B2, } \\
\text { B3,B4 }\end{array}$ & $\begin{array}{l}\mathrm{C} 1, \mathrm{C} 2 \\
\mathrm{C} 3, \mathrm{C} 4\end{array}$ & $\begin{array}{l}\text { D1,D2, } \\
\text { D3,D4 }\end{array}$ \\
\hline Table 1. $C$ & ssification of S & & Angl & \\
\hline
\end{tabular}

\begin{tabular}{|c|c|c|c|c|c|c|c|c|}
\hline Sample Type & \multicolumn{2}{|c|}{ Zero/basal } & \multicolumn{2}{|r|}{$24 \mathrm{~h}$} & \multicolumn{2}{|r|}{$48 \mathrm{~h}$} & \multicolumn{2}{|r|}{$72 \mathrm{~h}$} \\
\hline A (EDTA RT) & A1 & $41 \pm 9.3$ & A2 & $45 \pm 6.2$ & A3 & $44 \pm 5.2$ & A4 & $42 \pm 5.2$ \\
\hline B (EDTA COLD) & B1 & $37 \pm 7$ & B2 & $36 \pm 7.4$ & B3 & $33 \pm 5.4$ & B4 & $31 \pm 7.2$ \\
\hline C (SERUM ${ }_{\mathrm{RT}}$ ) & C1 & $27.8 \pm 2.5$ & $\mathrm{C} 2$ & $24.9 \pm 4.9$ & $\mathrm{C} 3$ & $22.3 \pm 2.3$ & $\mathrm{C} 4$ & $13 \pm 2.3$ \\
\hline D(SERUM COLD) & D1 & $25.3 \pm 6.3$ & D2 & $26 \pm 10.2$ & D3 & $27.2 \pm 5.5$ & D4 & $21 \pm 1.5$ \\
\hline
\end{tabular}

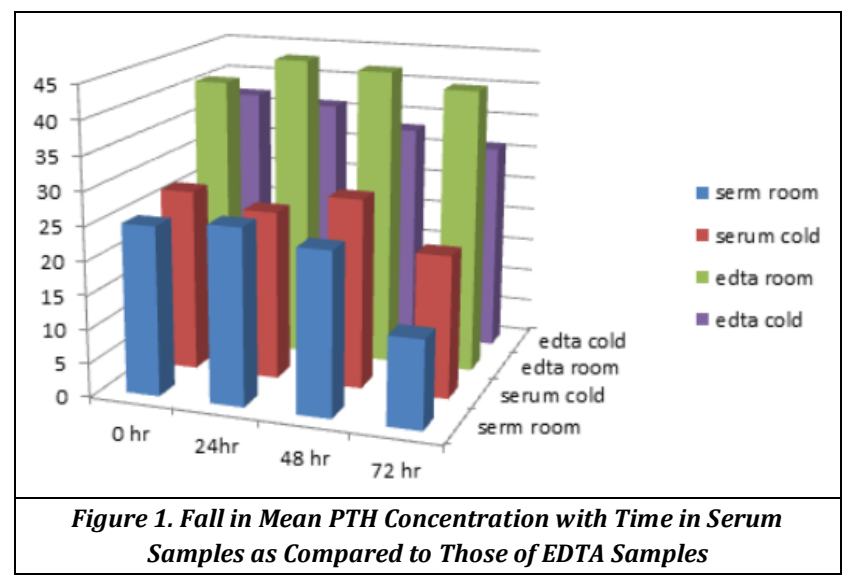

However, the serum RT at $24 \mathrm{~h}(\mathrm{M}=24.9, \mathrm{SD}=4.9)$ did not significantly differ from the serum RT at $48 \mathrm{~h}$. Taken together, these results suggest that time lapse do have a significant effect on iPTH results in the room temperature storage of serum type of sample. Plasma type of sample stored at cold or RT, did not show the significant difference in the results with the time lapse $(\mathrm{P}>0.05)$ for the first 2 days but they differ at $3^{\text {rd }}$ day. The effect of kind of storage (cold and RT) on the type (EDTA plasma and Serum) shows (Fig 1) that there is no influence of storing temperatures in serum till one day, but the gap was wide as the day 3 approaches. Whereas in plasma at RT the iPTH raised from day one and again back to basal value by day 3,but the cold plasma consistently decreased in value making a significant gap between cold and RT.

\section{DISCUSSION}

Results for specimens collected in EDTA were higher than those for specimens collected in SST tubes irrespective of temperature $(p<0.001)$. Time had no significant effect on PTH measurements in EDTA sample both at RT and cold except at $72 \mathrm{~h}$ of room temperature ( $p>0.01)$. In EDTA RT the iPTH concentrations there is no significant difference in all the four aliquots [A1, A2, A3, A4] [p> 0.06]. Whereas at room temperature, serum iPTH was declining by with the time lapse in measurement by $54 \%$. Newman et al, showed that PTH concentration decreases by $14 \%$ over 18 hrs. in serum and a study by Levin et al showed that the concentration of PTH decreased by $47 \%$ over 72 hrs., but did not decrease in

EDTA plasma.[9,10] These results are similar to our study results [11 percent in $18 \mathrm{hrs}$. and 54 percent in $72 \mathrm{hrs}$. seen in serum samples]. Radcliffe et al observed decrease of $17 \%$ in serum PTH over 24 hrs.[11] Russell and Henley showed a $30 \%$ decrease in measured PTH in serum at room temperature after $24 \mathrm{hrs}$. ${ }^{[12]}$ Teal et al showed significant decrease in serum samples after 24 and 48 hours, however their EDTA plasma samples showed a rise in PTH sample by $24 \mathrm{hrs}$. and a slight decrease by $48 \mathrm{hrs}$. which is still a little higher than base line value.[13] Same trend was observed in our study. Walker and Seth also found that Concentrations remained stable in EDTA plasma. ${ }^{[14]}$ A study by Gladening et al was showing similar outcome and found that after three days of storage, measured PTH concentration in EDTA had not decreased, but had declined by $40 \%$ in serum. At baseline, mean PTH in EDTA RT specimens was $9.8 \%$ higher than in EDTA cold specimens, our study showed a $9 \%$ high. This implies that even within $3 \mathrm{hrs}$. at room temperature, it will produce a shift in results for EDTA specimens to higher values. Interestingly, there was no significant difference in baseline PTH results for serum RT and cold. Thus, in the short term, SST serum specimens demonstrate greater stability, irrespective of temperature. However, after 48 and $72 \mathrm{~h}$, the mean measured PTH in serum RT specimens showed a greater percentage decrease from baseline. In this sense, PTH shows greater apparent stability in EDTA if the sample has to be transported and or there is a time lapse in measurements. Because "intact PTH" assays show cross-reactivity with PTH fragments, it is possible that apparent increases in PTH are attributable to fragment detection, i.e., fragments unique to the degradation process in EDTA plasma; no such increase is observed in serum samples.[15] If analysis occurs within $3 \mathrm{~h}$, SST serum affords the most consistent results, regardless of storage temperature. However, if a specimen remains at room temperature for several days before analysis, then EDTA-plasma results are less discrepant from their baseline.[16] Our data support this recommendation and further suggest that a 3-hr delay at room temperature will not affect results. DPC [Diagnostic Product Corporation] recommends that EDTA specimens be collected and maintained at $2-8{ }^{\circ} \mathrm{C}$. Our data suggest that this practice will prevent a paradoxical increase in PTH results as at $24 \mathrm{~h}$, there was a slight rise after a day in EDTA sample in room temperature.

\section{CONCLUSIONS}

Preanalytical issues in measuring the intact PTH concentrations like sample type and time lapse influence the results and can modify the clinical decisions. PTH concentrations are stable in EDTA plasma for about $72 \mathrm{hrs}$. at cold temperature compared to serum, making EDTA plasma a recommended sample for transporting samples in cold chain from remote areas to central laboratory up to 3 days. As each PTH method is affected differently by many pre-analytical factors, conclusions should not be drawn about other PTH assays based on these results.

\section{REFERENCES}

[1] Homes DT, Levin A, Forer B, et al. Preanalytical influences on DPC IMMULITE 2000 intact PTH assays of plasma and serum from dialysis patients. Clin Chem 2005;51(5):915-7.

[2] Endres DB, Rude RK. Mineral and bone metabolism. In: Burtis CA, Ashwood ER, eds. Tietz textbook of clinical 
chemistry. $2^{\text {nd }}$ edn. Philadelphia: WB Saunders 1994: p. 1914-22.

[3] Lepage R, Roy L, Brossard JH, et al. A non-(1-84) circulating parathyroid hormone (PTH) fragment interferes significantly with intact PTH commercial assay measurements in uremic samples. Clin Chem 1998;44(4):805-9.

[4] Glendenning P, Laffer LL, Weber HK, et al. Parathyroid hormone is more stable in EDTA plasma than in serum. Clin Chem 2002;48(5):766-7.

[5] Scharnhorst V, Valkenburg J, Vosters C, et al. Influence of preanalytical factors on the Immulite intact parathyroid hormone assay. Clin Chem 2004;50(5):974-5.

[6] Diagnostic Products Corporation. Reinstatement of EDTA as a sample type. Reference range and analytical sensitivity updates. Technical Bulletin \#2068. Breda, The Netherlands: Diagnostic Products Corporation, 2004.

[7] Clinical and Laboratory Standards Institute (formerly NCCLS). Procedures for the Handling and Processing of Blood Specimens; Approved Guideline - Third Edition. Wayne, PA: Clinical and Laboratory Standards Institute: 2004. NCCLS Document H18-A3.

[8] Intact PTH (iPTH) kit insert ADVIA Centaur $®$ ADVIA Centaur ${ }^{\circledR}$ XP Immunoassay Systems Ready Pack. 2011 Siemens Healthcare Diagnostics 10492444_EN Rev. C, 2014-02.
[9] Newman DJ, Ashby JP. Clinical and laboratory evaluation of a two-site immune radiometric assay for intact parathyroid hormone. Ann Clin Bio Chem 1988;25(Pt 6):654-60.

[10] Levin GE, Nisbet JA. Stability of parathyroid hormone related protein and parathyroid hormone at room temperature. Ann Clin Biochem 1994;31(Pt 5):497500.

[11] Ratcliffe WA, Heath DA, Ryan M, et al. Performance and diagnostic application of a two-site immunoradiometric assay for parathyrin in serum. Clin Chem 1989;35(9):1957-61.

[12] Russell D, Henley R. The stability of parathyroid hormone in blood and serum samples at 4 degree $C$ and at room temperature. Ann Clin Biochem 1995;32(Pt 2):216-7.

[13] Teal TK, Reed M, Stevens PE, et al. Stability of parathyroid hormone ex vivo in haemodialysis patients. Ann Clin Biochem 2003;40(Pt 2):191-3.

[14] Walker KS, Seth J. Stability of parathyroid hormone in blood from renal patients on haemodialysis. Ann Clin Biochem 2000;37(Pt 6):800-1.

[15] Blumsohn A, Al Hadari A. Parathyroid hormone: what are we measuring and does it matter? Ann Clin Biochem 2002;39(Pt 3):169-72.

[16] Diagnostic Products Corporation Netherlands. IMMULITE 2000 intact PTH [Package Insert] Product No. PIL2KPP-12. Breda, The Netherlands: Diagnostic Products Corporation, 2004. 